\title{
SEX RATIO CONSTANCY IN THE RED-WINGED BLACKBIRD
}

\author{
Kent L. Fiala ${ }^{1}$ \\ Museum of Zoology, University of Michigan, Ann Arbor, Michigan 48109
}

Received June 9, 1980. Revised January 13, 1981

The mean primary sex ratio (proportion of zygotes that are male) in most organisms with genetic sex determination is generally found to be very near $50 \%$. Although phenotypic variance about the mean is generally small and masked by the large sampling variance due to the binomial distribution of the sexes (Edwards, 1958,1970 ), the existence of loci modifying the sex ratio has been demonstrated in some organisms (Weir, 1953; Feinberg and Pimentel, 1966; Myers and Krebs, 1971; Beckenbach, 1978; others reviewed by Edwards, 1962a), and patterns of variation in the sex ratio of other organisms have occasionally been noted (see Parkes, 1926, for an early review). Trivers and Willard (1973), reviewing more recent mammalian data, proposed that facultative sex ratio variation is adaptive and is compatible with Fisher's (1958) hypothesis of evolution of the mean sex ratio. On the assumptions that (1) condition of young at the end of parental care will tend to be correlated with the condition of the mother during parental care, (2) differences in condition of the young at the end of parental care will tend to endure into adulthood, and (3) in polygynous species adult males are more greatly benefited by slight advantages in condition than are adult females, they hypothesized that mothers should bias their sex ratio in favor of males if they are in better than average condition for their population, and in favor of females if they are in poorer than average condition. Although Trivers and Willard considered only maternal condition, the logic of the argument applies to

\footnotetext{
1 Present address: Department of Ecology and Evolution, State University of New York, Stony Brook, Long Island, New York 11794.
}

any factor that might serve as a predictor of the relative reproductive value of offspring, such as, for example, genetic quality of the father.

The empirical support for the Trivers and Willard hypothesis comes almost entirely from previously published studies of mammals. Only Howe (1977) and Patterson and Emlen (1980) have yet reported data gathered with a test of the model in mind. The present study is another test of the model, in the red-winged blackbird Agelaius phoeniceus, which is a particularly suitable species in that it is parental (with most care being maternal), polygynous, and highly sexually dimorphic, and therefore could be expected a priori to meet the assumptions of Trivers and Willard.

\section{THEORY}

It is first necessary to re-examine Trivers and Willard's model to clarify what is expected when their conditions are met. Doing so reveals somewhat different properties than they supposed. I will interpret Trivers and Willard's model in terms of my, (1981) model of selection on the mean sex ratio, which I here briefly review and slightly generalize.

Assuming that a reproducing parent's current reproductive value, $C$, is a function of the numbers of sons, $M$, and daughters, $F$, that it produces, $C=$ $f_{1}(M, F)$, and that the parent's residual reproductive value, $R$, is another function of its clutch composition, $R=f_{2}(M, F)$, selection will tend to adjust the sex ratio such that

$$
\begin{aligned}
-\mathrm{d} M / \mathrm{d} F & =(\partial C / \partial F) /(\partial C / \partial M) \\
& =(-\partial R / \partial F) /(-\partial R / \partial M) .
\end{aligned}
$$

In words, the marginal rate of transformation of females for males equals the ra- 
tio of marginal value of females to marginal value of males, which equals the ratio of marginal cost of females to marginal cost of males.

Some specific information about the shapes of the $C$ and $R$ functions is necessary to specify the sex ratio. On the assumption that within each sex all offspring have the same reproductive value (i.e., $C$ is linear), the mean clutch composition that is favored by selection can be determined as follows. Consider a population in which the mean individual sex proportion (probability that a given offspring will be male) is $p$. If the proportion of genes in a remote future generation that are descended from genes currently in males is $k$, and if the population currently produces $n$ clutches, each averaging $M$ males and $F$ females, the collective reproductive value of males is $k n(M+F)$ and that of females is $(1-k) n(M+F)$. Thus the mean reproductive value per son is $k n(M+F) / n M=k / p$ and that per daughter is $(1-k) n(M+F) / n F=(1-k)$ / $(1-p)$, and thus (1) becomes

$$
\frac{-\mathrm{d} M}{\mathrm{~d} F}=\frac{1-k}{k} \frac{M}{F} .
$$

Because the relationship between relative marginal values of the sexes and the population sex ratio upon which the conclusion (2) depends applies only to the mean phenotype, that conclusion also applies only to the mean sex ratio. If there is phenotypic variation in $C$ as implied by Trivers and Willard's model, then for phenotype $i,\left(\partial C_{i} / \partial F\right) /\left(\partial C_{i} / \partial M\right)$ will depend in part on the population sex ratio but will also depend on the phenotype to the extent that phenotypic differences of parents affect the sexes of offspring unequally, as supposed by Trivers and Willard.

Similarly, there may be phenotypic variation in relative costs, $\left(-\partial R_{i} / \partial F\right)$ / $\left(-\partial R_{i} / \partial M\right)$. Effects of maternal condition on relative costs of the sexes will tend to be opposed to those on relative values. Mothers in good condition will, under Trivers and Willard's assumptions, tend to have higher than average values of $\left(-\partial R_{i} / \partial F\right) /\left(-\partial R_{i} / \partial M\right)$, and/or lower than average values of $\left(\partial C_{i} / \partial F\right) /\left(\partial C_{i} / \partial M\right)$; the opposite is true of mothers in poor condition. Because the mean values of these quantities are equal when the mean sex ratio is stable, the opposed differences insure that for no individual in a population with a stable mean sex ratio will the two quantities be equal, i.e., the optimal sex ratio for an individual is always either 0 or 1 (cf. Fig. 2 in Fiala, 1981).

Variation in marginal values and costs will of course affect not only sex ratio, but optimal levels of investment and clutch size as well; nevertheless the optimal sex ratio is always 0 or 1 (cf. Williams, 1979). Such extreme behavior is a general property of systems involving linear isocosts and isovalues (Nicholson, 1972); the peculiar feature that allows the mean sex ratio to equilibrate at an intermediate value is that the slope of the isovalues varies with the mean sex ratio, and tends to equal that of the isocosts (Fiala, 1981).

Two kinds of deviations from linearity would reduce the predicted severity of sex ratio variations. The first is concavity of the isovalues, i.e., that the equilibrial sexspecific values of offspring in mixed clutches are higher than in unisexual clutches. Such nonlinearity of $C$ may occur, for example, when local mate or resource competition (Hamilton, 1967; Clark, 1978) affects the reproductive opportunities of the sexes differently. The second is convexity of the isocosts, i.e., that the sex-specific costs of offspring in mixed clutches are less than in unisexual clutches. However there is usually no a priori reason to think either might be the case, and if they were, individuals would be selected to produce exactly (not just on average) the equilibrial sex ratio.

An alternative advantage for facultative sex ratios arises when the contributions of the two sexes to future generations are not equal, e.g., due to temporally varying deviations from a stable age distribution in a species with overlap of generations (Werren and Charnov, 1978). In this case, $k$ varies about its mean value of $1 / 2$ and the equilibrial proportion of males will tend to vary with $k$. The two models of 
facultative sex ratios differ in that Trivers and Willard predict individual variation about a constant population mean, while Werren and Charnov predict variation in the population mean. This paper is concerned only with the former pattern.

\section{Statistical Properties of Sex RATIO VARIATION}

Variance in the sex ratio can be detected either directly by comparing sex ratios among groups of mothers who share attributes thought to influence the sex ratio, or indirectly by testing for an added variance component in the variance of the overall sex distribution. The indirect method is useful for a preliminary test of the existence of any variation at all, especially when the variate hypothesized to affect sex ratio is not readily quantified.

If the probability of an individual offspring's being male (the mother's individual sex ratio) is a constant, $p$, for all offspring, then the number of males, $x$, in a clutch of size $n$ is a binomial random variable with mean $n p$ and variance $n p(1-$ $p$ ). Now suppose that $p$ varies among mothers, being $p_{i}$ for mother $i$. For each $p_{i}$ there is a distribution of $x$ with mean $n p_{i}$ and variance $n p_{i}\left(1-p_{i}\right)$ but the observer cannot distinguish the various overlapping distributions. The mean of $x$ is $n \bar{p}$, as in the simple binomial, but the variance of $x$ is greater than that of a binomial with the same mean, being $n \bar{p}$ $(1-\bar{p})+n(n-1) \operatorname{Var}(p)$. The distribution is known as the Lexian binomial (Edwards, 1960).

Alternatively, suppose that within a clutch, the value of $p$ varies from offspring to offspring, such that the probability that offspring $i$ is male is $p_{i}$, but that the $p_{i}$ 's are the same in each clutch. Then the observable variance of $x$ is less than if the sex ratio were constant, being $n \bar{p}(1-\bar{p})-n \operatorname{Var}(p)$. The distribution is known as the Poisson binomial (Edwards, 1960).

In principle then, these patterns of variation could be detected by a simple test of the variance of the observed sex distribution in each clutch size. The mathe- matical basis of this is closely related to that of conventional analysis of variance (David, 1949), in which Poisson variation is assumed not to exist, and a test is made for Lexian variation (cf. Sokal and Rohlf, 1969 , p. 219). Unfortunately the solution is not actually so simple because there are other mechanisms that can also increase or decrease the variance, most notably correlation between the sexes of successive offspring (Edwards, 1960; cf. Sokal and Rohlf, 1969, p. 75-77). Also, opposing factors could conceivably produce a net effect of zero on the variance. Edwards (1960) argues that for these reasons no useful inferences can be made from the fit of an observed distribution to the binomial, and has developed a more sophisticated method (Edwards, 1961, 1962b) which unfortunately requires almost unattainably large sample sizes. I do not feel that this criticism is relevant to the present problem. First, no mechanism for correlation between the sexes of successive young suggests itself for birds. Second, the Trivers and Willard hypothesis requires rather large Lexian variance. Lexian variance small enough to be counter-balanced exactly by Poisson variance could hardly be regarded as support for the hypothesis even if it could be detected by another method.

A numerical example may serve to clarify these points. Suppose that in a population in which all females produce four young each, females fall into five groups (indiscernible to an observer) according to their condition: the top $1 / 16$, the next best $1 / 4$, the middle $3 / 8$, the next best $1 / 4$, and the poorest $1 / 16$. Suppose that within these groups, the sex ratio in each clutch is, for each group respectively, exactly 100\%, $75 \%, 50 \%, 25 \%$, or $0 \%$. Then, because the various sex combinations will have the same frequency distribution as do the mothers, that distribution will be indistinguishable from a binomial, even though there is nothing binomial about the underlying process. The extreme pattern of variation among different categories of mothers on the one hand has interacted with the extreme invariance within classes 
TABLE 1. Hypothetical example of sex ratio variation.

\begin{tabular}{|c|c|c|c|c|c|c|c|}
\hline \multicolumn{2}{|c|}{$\begin{array}{c}\text { Clutch } \\
\text { composition }\end{array}$} & \multicolumn{5}{|c|}{ Mother's mean sex ratio } & \multirow[b]{2}{*}{ Row sum } \\
\hline Males & Females & $100 \%$ & $75 \%$ & $50 \%$ & $25 \%$ & $0 \%$ & \\
\hline 4 & 0 & 6.25 & 7.910 & 2.344 & .098 & & 16.602 \\
\hline 3 & 1 & & 10.547 & 9.375 & 1.172 & & 21.094 \\
\hline 2 & 2 & & 5.273 & 14.062 & 5.273 & & 24.608 \\
\hline 1 & 3 & & 1.172 & 9.375 & 10.547 & & 21.094 \\
\hline 0 & 4 & & .098 & 2.344 & 7.910 & 6.25 & 16.602 \\
\hline \multicolumn{2}{|c|}{ Column sum: } & 6.25 & 25.000 & 37.500 & 25.000 & 6.25 & 100.000 \\
\hline
\end{tabular}

to produce an artificial binomial. The possibility of a similar, if less extreme, occurrence in actual data underlies Edwards' (1960) criticism. But, to be slightly more realistic, suppose that the sex ratio within each group, rather than being invariant, is binomially distributed about the same mean as before. Then the frequency distribution of clutches produced by the various classes will be as in Table 1 , and the observable sex distribution will be as in the row sums of that table. This distribution is clearly recognizable as different from the binomial.

\section{Test for Sex Ratio Variation in THE RED-WINGED BLACKBIRD}

\section{Methods}

The study was conducted at the E. S. George Reserve, Livingston Co., Michigan, from 1974 to 1979. Four marshes were searched thoroughly each year for nests, which were then monitored until they became inactive.

Most nests were found before egg-laying was complete, and nearly all before hatching. In some years I marked eggs individually and measured their lengths and widths to the nearest $0.1 \mathrm{~mm}$ with a vernier caliper. In the last year I also weighed them on the day of laying to the nearest $0.05 \mathrm{~g}$ with a $10 \mathrm{~g}$ Pesola spring balance, shielded from wind by a clear acrylic cylinder.

An index of egg volume was computed by multiplying length by the square of diameter. This has been found to be an excellent predictor of hatchling weight in another icterid (Nolan and Thompson,
1978), and I found it to be highly correlated with fresh egg weight $(r=.982$, $d . f .=291, P \cong 0$ ).

Hatching synchrony was sufficient to make it unfeasible to associate many hatchlings with the egg from which they hatched, except that I could often identify the hatchling from the last egg laid. An individual was classified as being from the last egg if it hatched after all other nestmates had hatched and been individually marked, or if all the hatchlings were first observed on the same day but wet down or actual hatching was observed for one individual. I excluded from this classification last-hatched birds in nests in which one or more eggs failed to hatch unless each such egg was marked and known not to be the last one. I also excluded individuals thought to be last-hatched only on the basis of weight. Because the purpose of this classification was to estimate separately the sex ratio of last and non-last eggs, broods in which the sex of the last egg was known by default (all possibilities the same sex) might have been included but instead were classified with other sequence-unknown broods to avoid biasing the distribution toward unisexual clutches.

Nestlings were individually marked either by clipping a toenail or plucking a primary feather. Nestling weights were measured to the nearest $0.1 \mathrm{~g}$ with a $50 \mathrm{-g}$ Pesola spring scale.

Birds were sexed either by weight on day 8 or later, or by direct gonadal inspection, either by laparotomy (Fiala, $1979 b$ ) or by necropsy. On day 8 nearly all 
males exceed $33 \mathrm{~g}$, while nearly all females are less than $33 \mathrm{~g}$. Similar weight criteria have been reported reliable elsewhere (Williams, 1940; Haigh, 1968; Holcomb and Twiest, 1970; Fiala, 1981). Many young could not be sexed, in most cases due to failure to hatch or early death, but incompletely sexed broods were included in the analysis (Fiala, 1980) except for a few cases where some bias in sexing could have occurred. Sexing methods and possible biases are discussed in detail in Fiala (1979a).

Chi-square statistics and sex ratio regressions follow Snedecor and Cochran (1967), log-likelihood ratio $(G)$ statistics follow Sokal and Rohlf (1969), and other statistics were computed on the Michigan Interactive Data Analysis System.

\section{Assumptions}

Trivers and Willard imply that their assumptions are true for all polygynous parental animals with small clutch size. Actually verifying the assumptions for any particular species is difficult, and Trivers and Willard themselves rely on indirect, sometimes tenuous, evidence. In redwings, some support for the assumptions comes from the result that offspring growth rates vary seasonally (Table 2); initial size of nestlings varied less with hatching date than did weight attained at later ages, which tended to decline slightly with hatching date. This trend is not necessarily a simple function of female condition, but because returning yearlings tended to be those that were large as nestlings (Fiala, 1981), it satisfies the essence of the first two assumptions, which is that some information available to the mother predicts the relative fitness of her offspring. The same data also provide some support for the third assumption in that the seasonal decline in growth is more severe in males. The lack of significance in the female regressions on days 9 and 10 may be an artifact of early fledging of larger females and of earlier attainment of the temporary plateau in the growth curve (Fiala, 1981), but nevertheless at nearly all ages the regression slope is steeper
TABLE 2. Regressions of weight on hatching date.

\begin{tabular}{rrrrrrrr}
\hline \hline & \multicolumn{3}{c}{ Males } & & \multicolumn{3}{c}{ Females } \\
\cline { 2 - 3 } \cline { 6 - 7 } Age & Slope & $P$ & $N$ & & \multicolumn{1}{c}{ Slope } & \multicolumn{1}{c}{$P$} & $N$ \\
\hline 0 & .0006 & .85 & 393 & .0069 & .0147 & 418 \\
1 & .0044 & .44 & 274 & -.0012 & .82 & 291 \\
2 & -.0029 & .75 & 296 & -.0023 & .78 & 322 \\
3 & -.0032 & .85 & 198 & .0051 & .68 & 224 \\
4 & -.0237 & .37 & 188 & -.0183 & .36 & 189 \\
5 & -.0132 & .54 & 288 & -.0325 & .05 & 279 \\
6 & -.0671 & .07 & 191 & -.0171 & .36 & 205 \\
7 & -.1035 & .0006 & 232 & -.0487 & .0032 & 247 \\
8 & -.0442 & .0094 & 389 & -.0228 & .0152 & 429 \\
9 & -.0508 & .0116 & 234 & -.0098 & .43 & 212 \\
10 & -.0845 & .0011 & 149 & -.0076 & .62 & 101 \\
\hline
\end{tabular}

for males. Whether size differences are compensated for by later growth is unknown, and whether size variation of adults is correlated with reproductive success is questionable (Searcy, 1979), but the simple correlation of size and survival to breed satisfies the assumption.

\section{Distribution of the Sexes}

A total of 1,674 individuals (690 males, 766 females, and 218 unknowns) in 459 clutches was classified by sex. Excluding clutches incompletely sexed either because I distributed siblings among other broods before sexing them and some were later lost, or because of accidentally broken eggs, 432 clutches containing 664 males, 732 females, and 175 unknowns were available for analysis of the sex distribution. Ideally a test of the homogeneity of the sex ratio among mothers would simply be a comparison of the observed distribution of males and females among broods with a binomial distribution, but the occurrence of unsexed young complicates the matter. Under the broader null hypothesis that all young not only have the same probabilities of being male or female but also the same probability of dying unsexed, the distribution of males, females, and unknowns should be trinomial (Fiala, 1980). In the first years of the study the distribution was satisfactorily fit by the trinomial but in the full six years' data deviation from the null hypothesis became apparent.

The observed sex distribution is tabu- 
TABLE 3. Frequency distribution of sex combinations.

\begin{tabular}{|c|c|c|c|c|c|c|c|c|}
\hline \multicolumn{2}{|c|}{ Combination } & \multicolumn{5}{|c|}{ Clutch size } & \multirow[b]{2}{*}{$\begin{array}{l}\text { Frequency } \\
\text { (row sum) }\end{array}$} & \multirow[b]{2}{*}{$\begin{array}{l}\text { Expected } \\
\text { frequency }^{1}\end{array}$} \\
\hline$\delta 8$ & 90 & 2 & 3 & 4 & 5 & 6 & & \\
\hline 5 & 0 & & & & & & 0 & .19 \\
\hline 4 & 1 & & & & 1 & & 1 & 1.07 \\
\hline 3 & 2 & & & & 2 & & 2 & 2.37 \\
\hline 2 & 3 & & & & 4 & & 4 & 2.61 \\
\hline 1 & 4 & & & & 1 & & 1 & 1.44 \\
\hline 0 & 5 & & & & & & 0 & .32 \\
\hline 4 & 0 & & & 10 & & & 10 & 10.03 \\
\hline 3 & 1 & & & 42 & & & 42 & 44.24 \\
\hline 2 & 2 & & & 71 & 1 & & 72 & 73.15 \\
\hline 1 & 3 & & & 52 & 1 & & 53 & 53.76 \\
\hline 0 & 4 & & & 19 & & & 19 & 14.82 \\
\hline 3 & 0 & & 10 & 7 & & & 17 & 16.14 \\
\hline 2 & 1 & & 33 & 17 & & & 50 & 53.38 \\
\hline 1 & 2 & & 50 & 21 & & & 71 & 58.85 \\
\hline 0 & 3 & & 7 & 5 & & & 12 & 21.63 \\
\hline 2 & 0 & & 10 & 3 & & & 13 & 11.99 \\
\hline 1 & 1 & 7 & 12 & 8 & & & 27 & 26.44 \\
\hline 0 & 2 & 1 & 9 & 2 & & 1 & 13 & 14.57 \\
\hline 1 & 0 & 2 & 4 & 1 & & & 7 & 7.61 \\
\hline 0 & 1 & 2 & 5 & 2 & & & 9 & 8.39 \\
\hline 0 & 0 & 1 & 3 & 5 & & & 9 & \\
\hline Sum & & 13 & 143 & 265 & 10 & 1 & 432 & 432 \\
\hline
\end{tabular}

Numbers of males and females sexed in a clutch are given on the left. The number of unsexed young can be obtained by subtracting the sum these numbers from the clutch size.

Expected frequencies are based on binomial distributions fitted separately for each subgroup of data with a given number of sexed young per clutch, but using the overall sex ratio throughout.

lated by clutch size in Table 3. Only clutches of three or four are numerous enough for trinomial goodness-of-fit tests. Lumping cells with expectations less than one with the next least likely cell so that all expectations are at least one, the test statistic for clutches of three is $\chi^{2}=16.91$ (6 d.f., $P<.01$ ) and for clutches of four is $\chi^{2}=29.27$ (9 d.f., $P<.001$ ). The largest contribution to $\chi^{2}$ is made by the clutches in which no young were sexed, due to infertility of the entire clutch. (A great many clutches had no sexed young, due to predation; these are of course ignored.)

Rejection of the trinomial hypothesis does not in itself identify the source of the deviation. Variation in the sex ratio among mothers could produce a deviation from the trinomial, but so could variation among mothers in fertility, hatchability, or neonatal mortality of their eggs or young, and these hypotheses must be investigated separately, as follows.

Under the hypothesis that each egg is equally likely to die unsexed, the distribution of sexed and unsexed young should be binomial. The observed distributions (Table 4) are in fact clearly not binomial for either clutches of four (goodness-of-fit $\chi^{2}=15.5,1 d . f$. with last three classes lumped, $P<.0001$; heterogeneity $\chi^{2}=$ $469,264 d . f ., P \cong 0$ ) or clutches of three (goodness-of-fit $\chi^{2}=7.46,1 d . f ., P<$ .01 ; heterogeneity $\chi^{2}=201,142 d . f$., $P<.001)$. A modified binomial which assumes the survival probability to be a $\beta$-variate (Edwards, 1958) fits much better, and the negative binomial fits better still (Table 4). These results could reflect either Lexian variation in the probability of dying unsexed, i.e. within a brood the probability is relatively constant but it varies among broods, or a correlation 
TABLE 4. Frequency distributions of sexed and unsexed young in clutches of four and three.

\begin{tabular}{ccccccc}
\hline \hline \multicolumn{2}{c}{ Combination } & & & \multicolumn{3}{c}{ Expected frequencies } \\
\cline { 6 - 7 } Sexed & Unsexed & $\begin{array}{c}\text { Observed } \\
\text { frequency }\end{array}$ & & $\begin{array}{c}\text { Negative } \\
\text { binomial }\end{array}$ & $\begin{array}{c}\text { Modified } \\
\text { binomial }\end{array}$ & $\begin{array}{c}\text { Simple } \\
\text { binomial }\end{array}$ \\
\hline 4 & 0 & 194 & 194.3 & 198.1 & 174.6 \\
3 & 1 & 50 & 48.1 & 40.5 & 76.8 \\
2 & 2 & 13 & 15.0 & 17.0 & 12.6 \\
1 & 3 & 3 & 5.0 & 7.2 & .93 \\
0 & 4 & 5 & 1.7 & 2.3 & .026 \\
3 & 0 & 100 & 99.6 & 97.2 & 92.5 \\
2 & 1 & 31 & 32.3 & 35.4 & 63.4 \\
1 & 2 & 9 & 8.5 & 9.1 & .35 \\
0 & 3 & 3 & 2.0 & 1.3 & 6.8 \\
\hline
\end{tabular}

${ }^{1}$ Probability of dying unsexed assumed to have a $\beta$-distribution among nests.

among such mortalities, i.e., if one egg is infertile, dies, etc., it increases the probability that the same thing will happen to another member of the clutch. There does not appear to be any way to separate the two possibilities.

Because the probability of dying unsexed is a variable (rather than a constant, as I have assumed elsewhere [Fiala, 1980]), the sex distribution of the sexed young would not be expected to be binomial unless mortality is independent of sex. Varying sex-specific mortality might be reflected in variation of the sex ratio with the number of unsexed young; thus absence of such variation in red-wings (Table 5) suggests an absence of differential mortality prior to sexing, and supports the continued use of the binomial as the expected distribution of sexed birds under the null hypothesis of no sex ratio variation.

Table 3 shows expected frequencies of brood combinations, calculated by fitting a separate binomial for each brood size,

TABLE 5. Sex ratio in completely and incompletely sexed clutches.

\begin{tabular}{lccr}
\hline & Males & Females & \multicolumn{1}{c}{ Total } \\
\hline Completely sexed & 532 & 600 & 1,132 \\
Incompletely sexed & 132 & 132 & 264 \\
Total & 664 & 732 & 1,396 \\
\hline
\end{tabular}

but using the overall sex ratio for each. In general the fit is very good $\left(\chi^{2}=10.18,14\right.$ d.f., $P>.5$, with most of the contribution to the Chi-square coming from the considerable excess of combinations of one male and two females, and shortage of combinations of three females. Though the same deviation occurs to some extent both in clutches of three and of four, it is not explicable as anything but fortuitous. It does not reflect any real difference between broods of three and other sizes, as there is no overall interaction between clutch size and the distribution of males, females and unknowns, nor between the sex ratio in clutches of three versus other clutches, nor between sexed and unsexed young in clutches of three versus other clutches (Fiala, 1979a).

\section{Sex Ratio Correlates}

The failure of the trinomial model thus appears to be due only to the failure of the binomial model for the distribution of mortality. The case for the binomial distribution of the sexes appears sound. But for reasons previously discussed, failure to reject the null hypothesis of binomial distribution does not necessarily prove the existence of a simple binomial mechanism. In this section I discuss my search for specific correlates of the sex ratio that might produce hidden Poisson or Lexian variation.

\section{Factors tending to reduce variation of}


Table 6. Sex and egg sequence.

\begin{tabular}{lrrrr}
\hline & & \multicolumn{3}{c}{$\begin{array}{c}\text { Sex } \\
\text { un- }\end{array}$} \\
\hline In clutches of four & & & & \\
$\quad$ Mastes egg of four & 42 & 70 & 10 & 122 \\
$\quad$ Females & & & Total \\
$\quad$ First 3 of 4 & 178 & 176 & 12 & 366 \\
Sequence unknown & 231 & 258 & 83 & 572 \\
$\quad$ Total & 451 & 504 & 105 & 1,060 \\
\hline In clutches of three & & & & \\
$\quad$ Last egg of 3 & 23 & 20 & 4 & 47 \\
First 2 of 3 & 38 & 45 & 11 & 94 \\
Sequence unknown & 121 & 124 & 43 & 288 \\
$\quad$ Total & 182 & 189 & 58 & 429 \\
\hline
\end{tabular}

the sex distribution. - The only variancereducing factor that seems relevant to birds is a systematic variation of the sex ratio with laying sequence. The alternative mechanism suggested for humans by Edwards (1960), negative correlation between the sexes in successive conceptions, seems a priori unlikely in birds since young are produced in clutches rather than singly.

I investigated the possibility of relationship between egg sequence and sex directly by comparing last-egg young with others (Table 6). No relationship between classification by sex and sequence is indicated in clutches of three $(G=2.60,4$ $d . f$ ), but a highly significant pattern occurs in clutches of four $(G=41.84,4 d . f$., $P \cong 0$ ). I have subdivided the overall contingency table for clutches of four into four independent two-by-two contingency tables (Table 7) whose $G$ statistics partition the overall $G$ statistic. Each of these tests a relevant null hypothesis, as follows: (A) Among eggs that were sexed and identified as last or non-last, the sex ratio is independent of sequence position. The hypothesis is rejected $(P<.05)$; there is a distinct female bias in last eggs. (B) The probability that $I$ could determine the sex of an egg is independent of the probability that I could determine its sequence position. This hypothesis is also rejected $(P<.05)$; I was more likely to fail to sex last eggs. One possible, but not necessary, implication of this result is that there was not an actual bias in the sex ratio of last eggs, but that last-hatched males were more likely to die before sexing than were females. (C) There is no difference in the sex ratio of sexed young between clutches with the last egg identified and those with sequence unknown. Such a difference might have arisen if there was a sex ratiodependent difference in hatching synchrony, but the null hypothesis is not rejected. (D) There is no interaction between the likelihood of recognizing the last young and determining its sex. This hypothesis is rejected $(P \cong 0)$. The high significance of the correlation is an artifact of method, primarily because of the impossibility of recognizing the last egg, if not marked, in nests in which not all eggs hatched.

As an indirect test of a relationship between sex ratio and laying sequence, I compared sex ratios associated with different relationships between egg size and laying sequence. I examined the relation-

TABLE 7. Four independent partitions of sex and egg sequence data for clutches of four.

\begin{tabular}{|c|c|c|c|c|c|c|c|c|}
\hline & & Males & Females & Total & & $\begin{array}{c}\text { Sex } \\
\text { known }\end{array}$ & $\begin{array}{c}\text { Sex } \\
\text { unknown }\end{array}$ & Total \\
\hline $\begin{array}{l}\text { Last egg of } 4 \\
\text { First } 3 \text { of } 4\end{array}$ & A. & $\begin{array}{r}42 \\
178\end{array}$ & $\begin{array}{r}70 \\
176\end{array}$ & $\begin{array}{l}112 \\
354\end{array}$ & B. & $\begin{array}{l}112 \\
354\end{array}$ & $\begin{array}{l}10 \\
12\end{array}$ & $\begin{array}{l}122 \\
366\end{array}$ \\
\hline \multirow[t]{2}{*}{ Total } & & 220 & 246 & 466 & & 466 & 22 & 488 \\
\hline & \multicolumn{6}{|c|}{$G=5.64$} & \multicolumn{2}{|c|}{$G=4.55$} \\
\hline $\begin{array}{l}\text { Sequence known } \\
\text { Sequence unknown }\end{array}$ & C. & $\begin{array}{l}220 \\
231\end{array}$ & $\begin{array}{l}246 \\
258\end{array}$ & $\begin{array}{l}466 \\
489\end{array}$ & D. & $\begin{array}{l}466 \\
489\end{array}$ & $\begin{array}{l}22 \\
83\end{array}$ & $\begin{array}{l}488 \\
572\end{array}$ \\
\hline \multirow[t]{2}{*}{ Total } & & 451 & 504 & 955 & & 955 & 105 & 1,060 \\
\hline & \multicolumn{6}{|c|}{$G=0$} & \multicolumn{2}{|c|}{$G=31.65$} \\
\hline
\end{tabular}




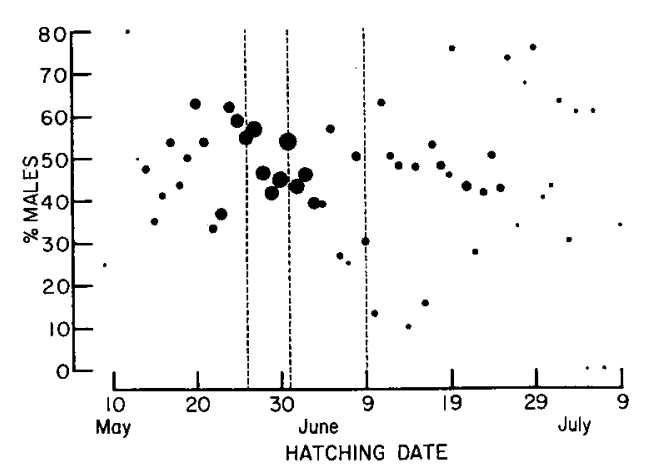

FIG. 1. Sex ratio as a function of hatching date. Data from 1974-1979 are pooled. The area of each circle is approximately proportional to the number of young hatched on each date $(\max N=95)$. The dashed bars indicate the quartiles of the distribution.

ship between egg size and sequence using the null hypothesis that if there is no relationship between an egg's size and its position in the laying sequence, then if eggs within a clutch are ranked by size, each possible rank sequence is equally likely. This test is sensitive to the existence of any pattern, linear or not. There are 115 clutches of four eggs and 54 clutches of three for which I have complete data for both size and sequence. A few clutches had ties in egg size; these clutches were divided equally between the possible rank sequences. There is a highly significant relationship between position and egg size in both clutch sizes (clutches of four: $\chi^{2}=$ 156.7, $23 d . f ., P \cong 0$; clutches of three: $\left.\chi^{2}=24.8,5 d . f ., P<.001\right)$. In the case of clutches of four there is a clear tendency for size to increase with sequence $(28.5$ clutches were strictly increasing), but in clutches of three, opposing tendencies either to increase or decrease are apparent. If this strong size-sequence relationship were associated with a sex-sequence relationship, it might be expected that variation in the size-sequence pattern would be associated with variation in the sex ratio. But there does not appear to be any correlation of sex with sequence pattern in either clutches of four $\left(\chi^{2}=18.3\right.$, $23 d . f$. , ) or of three $\left(\chi^{2}=5.1,5 d . f\right.$. $)$.

Factors tending to increase variance of the sex distribution.-The mechanism for increased variance that seems relevant to birds is variation in the mean sex ratio among mothers. Positive correlation between successive conceptions, like negative correlation, seems unlikely. I examined egg size, hatching date, clutch size, and harem size for possible correlation with sex ratio.

To test for an egg size effect, I grouped completely sexed clutches of four for which I have egg size data according to sex composition, and computed a twolevel analysis of variance of egg size, with clutches nested within sex ratio. There is no significant difference between egg sizes in clutches with different sex ratios, though there is highly significant variation among clutches within sex ratios $(F=$ $18.8, d . f .=62,201, P \cong 0$ ).

There was a general, though slight, decrease in the sex ratio with increasing hatching date, but the overall trend is not significant. Nonetheless, graphical representation of the data (Fig. 1) suggests that the trend may be real over part, but not all, of the breeding season. Regressions and probit analyses computed over the middle $50,60,70,80$, and 85 percentiles of the distribution are significant at the .05 to .01 levels. Covariance analysis shows no significant among year variation in slope.

The non-uniformity of the apparent trend through the season could be the result of variation due to another independent variable correlated with date; possibilities include maternal age, renesting, and clutch size. Yearling females are known to begin nesting substantially later in the season than do older females (Jackson, 1971; Crawford, 1977); Crawford reports a difference of 15 days in mean date of clutch initiation. If, for example, yearling females produce a lower sex ratio, this would account for the transient decline in the sex ratio. Also, females regularly renest after failure of an initial nesting attempt (Jackson, 1971), and occasionally after a successful first nest. If older females are more likely to renest, but produce the same sex ratio in renests, it could account for the termination of the sex ratio 
TABLE 8. Sex ratio and harem size.

\begin{tabular}{ccccc}
\hline \multirow{2}{*}{$\begin{array}{c}\text { Harem } \\
\text { size }^{1}\end{array}$} & $\begin{array}{c}\text { Number } \\
\text { of } \\
\text { harems }\end{array}$ & \multicolumn{3}{c}{ Sexed offspring } \\
\cline { 3 - 5 } 1 & 11 & 11 & 14 & Males \\
2 & 20 & 42 & 43 & Females \\
3 & 20 & 62 & 82 & 144 \\
4 & 7 & 31 & 33 & 64 \\
5 & 3 & 15 & 17 & 32 \\
6 & 3 & 24 & 27 & 51 \\
7 & 2 & 16 & 22 & 38 \\
& & 201 & 238 & 439 \\
\hline
\end{tabular}

${ }^{1}$ See text.

decrease late in the season. I have too few data on female age to test these hypotheses.

Clutch size decreases very slightly as the season progresses $(b=-.0073 \mathrm{eggs} / \mathrm{day}$, $\left.r^{2}=.024, P<.005\right)$. This trend could be related to the sex ratio as a manifestation of the decreasing mean age of mothers, since inexperienced females are known to produce smaller clutches than do experienced breeders (Jackson, 1971; Crawford, $1977)$, or as an adaptation to seasonal deterioration of breeding conditions. With the first five years' data, inclusion of both date and clutch size in the probit model produced a significant though weak fit, but the fit was poorer with the addition of the 1979 data. There is now no suggestion of an association between clutch size and sex ratio $(G=3.07,4 d . f$.$) .$

Finally, I computed sex ratio as a function of an estimate of harem size (Table 8) in two marshes in 1977 and three marshes in 1978 in which all territorial males were individually marked. Harem size could not be exactly determined because few adult females were individually marked, so I have used an estimate of the minimum number of different females, based on temporal spacing of nests (Searcy, 1979). Although some individual harems produced rather skewed sex ratios, no consistent pattern was apparent and there was no overall heterogeneity due to harem size $(G=1.35,6 d . f$.$) . Patterson and Em-$ len (1980) also found no relationship between harem size and sex ratio in the closely related yellow-headed blackbird, Xanthocephalus xanthocephalus.

\section{Discussion}

Though cogent, Trivers and Willard's hypothesis is not well supported by data, especially when one takes into account my demonstration that their assumptions lead to the expectation of even more extreme variation than they supposed, or than has been reported in diploids with genetically determined sex (except in some instances in which other causes have been identified [Johnson, 1977; Stenseth, 1978]).

The result that extreme, all-or-none variation is predicted is not as surprising as it may first appear; there is some analogy with the well-known result in optimal foraging theory (e.g., Pulliam, 1974) that organisms should always take profitable prey and always reject unprofitable prey, with no partial preferences. However this is not to say that theoretical conditions for partial sex ratio bias do not exist, only that if so they have not been identified. It may be, for example, that the assumption (Fiala, 1981) that natural selection maximizes the malthusian parameter is incorrect, or that I have not identified relevant constraints. Optimization models in which minimization of variance of fitness is important have been derived both analytically (Gillespie, 1977) and by simulation (Thompson et al., 1974), and the addition of constraints to one optimal foraging model has been shown to predict partial preferences (Pulliam, 1975).

For these reasons it remains worth while to examine critically the extent of sex ratio variation in nature. In doing so it is, as pointed out by Myers (1978), essential to avoid confusion between adaptive modification of the conceived sex ratio and post-conception modification. The latter may well be adaptive, but at best its inefficiency implies compromise (indeed a limitation on the number of excess zygotes that can be produced could be one constraint limiting the range of sex ratio variation if all adjustment is post-fertilization). The problem is that it is difficult to 
tell whether sex ratio alteration is ultimate cause or only proximate effect of differential mortality. Supporting data cited by Trivers and Willard do not permit resolution of this problem.

For identifying variation of the primary sex ratio (as opposed to post-meiotic modification), the choice of a bird as a study organism has the advantage that, due to female heterogamety and oviparity, birds have fewer means of varying the sex ratio than do mammals. In birds the sex determining reduction division occurs after the ovum is fully enlarged, just before ovulation (Olsen, 1942). Ova that reach a critical size are always ovulated (Payne, 1969), and in red-wings at least the number of ova that will be ovulated is determined a few days in advance of clutch completion (Payne, 1969). Thus, sperm selection is irrelevant, selective fertilization of ova and selective resorption of $z y-$ gotes are ruled out, and non-fertilization of an ovum of an undesirable sex is disadvantageous because the ovum cannot be replaced. Any sex ratio variation that might be observed could be rather confidently attributed to modification of segregation (Howe, 1977).

But, as has been found in other organisms (Williams, 1979), the evidence for variation is weak. The strongest evidence is that in the common grackle, Quiscalus quiscula (Howe, 1977), and in red-wings the sex ratio appears to change seasonally. Although the regression for grackles was significant over the entire sample whereas that for red-wings was significant over only the peak of the season, the difference is likely an artifact of Howe's sampling only first nests. The intriguing comparison between these trends is that while each appears to be adaptive in that the proportion of males is higher in the more favorable part of the season, the regressions have opposite signs. In grackles the sex ratio increases with time while in redwings it decreases. This makes it unlikely that the trends are fortuitous physiological effects. Seasonal trends have also been reported in the sex ratio of pigeon hybrids by Riddle (1917), but he did not evaluate his data statistically.

Even if it is real the seasonal trend in the red-wing sex ratio accounts for only a minute fraction of the total variation in the sex distribution. Lack of variation in sex ratio with egg size, clutch size, or harem size, and the lack of demonstrable deviation from a binomial distribution of the sexes support the view that facultative variation of the primary sex ratio is at best too modest to be taken as support of the Trivers and Willard hypothesis. At the same time, the uncertain female bias in last eggs is but scant evidence for a tendency toward sex ratio homeostasis (Williams, 1979; Taylor and Sauer, 1980).

The red-wing sex ratio has now been shown to differ from that predicted theoretically in both mean (Fiala, 1981) and variance, in neither case with an entirely satisfactory alternative explanation. Such results are somewhat disappointing, for they leave unresolved the test of the null hypothesis that the sex ratio is simply what meiosis produces (Maynard Smith, 1978). Though the slight deviations that have been identified in both mean and variance do provide at least a suggestion against the null hypothesis, it may be that meiosis is stabilized by selection below the individual level.

\section{SUMMARY}

Trivers and Willard (1973) hypothesized that under assumptions valid for many polygynous animals, females should be capable of varying the sex ratio of their offspring according to their own condition. In the absence of any additional constraints the predicted variation is even greater than Trivers and Willard realized; the optimal sex ratio for an individual to produce is always 0 or 1 .

Red-winged blackbirds appear to satisfy the assumptions of the model and thus are expected to have a variable sex ratio. But, as manifested by lack of deviation from the binomial distribution of the sexes and by lack of correlation of sex ratio with laying sequence, egg size, clutch size, or 
harem size, the sex ratio appears to be constant. The strongest evidence of variation is a very slight seasonal decline in the sex ratio, but the magnitude of variation is far too small to be taken as support for the hypothesis. The results are not accounted for by current theory.

\section{ACKNOWLEDGMENTS}

During parts of the study, I received support from an NSF graduate fellowship, a Rackham dissertation grant, and a Hinsdale scholarship. I thank G. F. Estabrook, P. Myers, R. B. Payne, W. A. Searcy, and G. C. Williams for comments on the manuscript

\section{Literature Cited}

Beckenbach, A. T. 1978. The "sex-ratio" trait in Drosophila pseudoobscura: fertility relations of males and meiotic drive. Amer. Natur. 112:97117.

ClaRk, A. B. 1978. Sex ratio and local resource competition in a prosimian primate. Science 201:163-165.

CRAWFORD, R. D. 1977. Breeding biology of yearold and older female red-winged and yellowheaded blackbirds. Wilson Bull. 89:73-80.

David, F. N. 1949. Probability Theory for Statistical Methods. University Press, Cambridge.

EDWARDs, A. W. F. 1958. An analysis of Geissler's data on the human sex ratio. Ann. Human Genet. 23:6-15.

- 1960. The meaning of binomial distribution. Nature 186:1074.

- 1961. A factorial analysis of sex ratio data. Ann. Human Genet. 25:117-121.

- 1962a. Genetics and the human sex ratio. Adv. Genet. 11:239-272.

- 1962b. A factorial analysis of sex-ratio data: a correction to the article in Vol. 25:117. Ann. Human Genet. 25:343-346.

- 1970. The search for genetic variability of the sex ratio. J. Biosoc. Sci., Suppl. 2:55-60.

Feinberg, E. H., AND D. Pimentel. 1966. Evolution of increased "female sex ratio" in the blowfly (Phaenicia sericata) under laboratory competition with the house fly (Musca domestica). Amer. Natur. 100:235-244.

FialA, K. L. 1979a. Natural selection and the sex ratio in the red-winged blackbird. Ph.D. Dissertation. Univ. Michigan, Ann Arbor.

-. 1979b. A laparotomy technique for nestling birds. Bird Banding 50:366-367.

_ _. 1980. On estimating the primary sex ratio from incomplete data. Amer. Natur. 115:442444.

- 1981 . Reproductive cost and the sex ratio in red-winged blackbirds, p. 198-214. In R. D.
Alexander and D. W. Tinkle (eds.), Natural Selection and Social Behavior: Recent Research and New Theory. Chiron Press. In press.

Fisher, R. A. 1958. The Genetical Theory of Natural Selection, 2nd rev. ed. Dover, N.Y.

GiLlesPIE, J. H. 1977. Natural selection for variances in offspring numbers: a new evolutionary principle. Amer. Natur. 111:1010-1014.

HaIGH, C. R. 1968. Sexual dimorphism, sex ratios and polygyny in the red-winged blackbird. Ph.D. Dissertation. Univ. Washington.

Hamilton, W. D. 1967. Extraordinary sex ratios. Science $156: 477-488$.

HolcomB, L. C., AND G. Twiest. 1970. Growth rates and sex ratios of red-winged blackbird nestlings. Wilson Bull. 82:294-303.

Howe, H. F. 1977. Sex-ratio adjustment in the common grackle. Science 198:744-746.

JACKson, J. J. 1971. Nesting ecology of the female redwinged blackbird (Agelaius phoeniceus phoeniceus). Ph.D. Dissertation. Ohio State Univ.

Johnson, C. 1977. Evolution of sex ratios in the isopod, Venezillo evergladensis. Evolution 31:603610.

Maynard Smith, J. 1978. The Evolution of Sex. Cambridge Univ. Press, Cambridge.

MYeRs, J. H. 1978. Sex ratio adjustment under food stress: maximization of quality or numbers of offspring? Amer. Natur. 112:381-388.

Myers, J. H., AND C. J. KREBS. 1971. Sex ratios in open and enclosed vole populations: demographic implications. Amer. Natur. 105:325-344.

Nicholson, W. 1972. Microeconomic Theory. Dryden Press, Hinsdale, Ill.

Nolan, V., JR., and C. F. Thompson. 1978. Egg volume as a predictor of hatchling weight in the brown-headed cowbird. Wilson Bull. 90:353358.

OLSEN, M. W. 1942. Maturation, fertilization, and early cleavage in the hen's egg. J. Morph. 70:513-533.

PARKes, A. S. 1926. The mammalian sex-ratio. Biol. Rev. and Biol. Proc. Cambridge Phil. Soc 2:1-51.

Patterson, C. B., ANd J. M. Emlen. 1980. Variation in nestling sex ratios in the yellow-headed blackbird. Amer. Natur. 115:743-747.

PAyne, R. B. 1969. Breeding seasons and reproductive physiology of tricolored and redwinged blackbirds. Univ. Cal. Publ. Zool. 90:1-137.

Pulliam, H. R. 1974. On the theory of optimal diets. Amer. Natur. 108:59-74.

- 1975. Diet optimization with nutrient constraints. Amer. Natur. 109:765-768.

RidDle, O. 1917. The control of the sex ratio. J. Wash. Acad. Sci. 7:319-356.

SEARCY, W. A. 1979. Male characteristics and pairing success in red-winged blackbirds. Auk 96:353-363.

Snedecor, G. W., and W. G. Cochran. 1967. Statistical Methods. Iowa State Univ. Press, Ames.

SokAl, R. R., AND F. J. Rohlf. 1969. Biometry. W. H. Freeman and Co., San Francisco. 
Stenseth, N. C. 1978. Is the female biased sex ratio in wood lemming Myopus schisticolor maintained by cyclic inbreeding? Oikos 30:8389.

Taylor, P. D., AND A. Sauer. 1980. The selective advantage of sex-ratio homeostasis. Amer. Natur. 116:305-310.

Thompson, W. A., I. Vertinsky, and J. R. KREBS. 1974. The survival value of flocking in birds: a simulation model. J. Anim. Ecol. 43:785-820.

Trivers, R. L., AND D. E. Willard. 1973. Natural selection of parental ability to vary the sex ratio of offspring. Science 179:90-92.
WEIR, J. A. 1953. Association of blood-pH with sex ratio in mice. J. Hered. 44:133-138.

Werren, J. H., and E. L. Charnov. 1978. Facultative sex ratios and population dynamics. Nature 272:349-350.

Williams, G. C. 1979. The question of adaptive sex ratio in outcrossed vertebrates. Proc. R. Soc. London B 205:567-580.

Williams, J. F. 1940. The sex ratio in nestling eastern red-wings. Wilson Bull. 52:267-277.

Corresponding Editor: H. M. Wilbur

Society for the Study of Evolution and

American Society of Naturalists

1982 Meetings

State University of New York at Stony Brook

Stony Brook, New York

June 21-24, 1982

Symposia will be held on Coevolution, The History of Evolutionary Controversy, and The Evolution of Genes and Proteins. The afternoon session of June 23 and the entirety of June 24 will be devoted to The Evolution of Genes and Proteins. Contributed paper sessions will be held on the afternoons of June 21 and 22 and the morning of June 23. Additional information can be obtained from

The Organizing Committee 1982 SSE and ASN

Department of Ecology and Evolution

State University of New York

Stony Brook, N.Y. 11794 